\title{
Contribuições das Sequências de Ensino Investigativas (SEI) aos Alunos de Medicina em Imersão na PBL
}

Contributions of Inquiry-based Teaching-learning Sequences for Medicine Students in PBL Immersion

\author{
Prislaine Pupolin Magalhães ${ }^{1}$ \\ Silvia Regina Quijadas Aro Zuliani
}

\section{Resumo}

A Aprendizagem Baseada em Problemas (PBL) tem sido adotada em diversas instituições de ensino superior, visando promover a autonomia, pesquisa e interdisciplinaridade. Buscamos, nesta pesquisa, verificar as potencialidades da inserção das SEl (Sequência de Ensino Investigativa) nos currículos PBL para alunos em fase inicial de formação em medicina. Após a aplicação de uma SEI previamente validada e publicada, realizamos a coleta de dados, cuja análise de conteúdo com categorias estabelecidas a posteriori resultou em três categorias consensuais para professores e alunos. Os resultados apontaram a necessidade de adaptação didático-pedagógica, na qual a inserção da SEI se apresentou promissora. Concluímos que estratégias metodológicas como as SEl podem ser uma alternativa para preparar professores e alunos para tais mudanças, fazendo com que construam subsídios para resolverem problemas reais no futuro, em uma proposta mais crítica e humanizada.

Palavras chave: Aprendizagem Baseada em Problemas; Adaptação à PBL; Sequência de Ensino Investigativa; SEl.

\section{Abstract}

Problem-Based Learning (PBL) has been adopted in several Higher Educational Institutions, aiming to promote autonomy, research and interdisciplinarity. In this research we seek to verify the potential for the insertion of an Inquiry-based Teaching-learning Sequence (ITS) in the PBL curricula, for students in the initial phase of medical training. After applying an ITS previously validated and published, we performed data collection, whose content analysis with categories established posteriori, resulted in three consensual categories for teachers and students. The results pointed out the need for didactic-pedagogical adaptation, where the insertion of ITS was promising. We conclude that methodological strategies such as ITS, can be an alternative to prepare teachers and students for the changes, making them build subsidies to solve real problems in the future, in a more critical and humanized proposal.

Keywords: Problem Based Learning. PBL. Inquiry-based Teaching. Inquiry-based Teachinglearning Sequences.

\footnotetext{
${ }^{1}$ Universidade Estadual Paulista - UNESP | prislaine.magalhaes@unesp.br

2 Universidade Estadual Paulista - UNESP | silvia.zuliani@unesp.br
} 


\section{Introdução}

Atualmente, os currículos dos cursos superiores na área de ciências da saúde estão abandonando suas características tradicionais e passando por grandes reestruturações para propiciar a aquisição de competências que estejam de acordo com o mundo contemporâneo (TEÓFILO et al., 2017, GOMES et al., 2009), visando atender aos anseios do aluno e produzir uma formação mais alinhada à prática e necessidades regionais.

Faz-se necessário, no ensino de ciências, discutirmos sobre essas mudanças. Este texto traz reflexões sobre a inserção de metodologias bem fundamentadas e discutidas para o ensino de conteúdos específicos no ensino básico, assim como sua proposta de aplicação no ensino superior.

O presente artigo traz um recorte da dissertação de mestrado intitulada Sequências de Ensino Investigativas (SEI) e Aprendizagem Baseada Em Problemas (PBL): Aproximações Teórico Metodológicas e suas Contribuições aos Alunos de Medicina em Fase Inicial de Formação e professores, que teve como objetivo avaliar as contribuições da aplicação de uma SEl para alunos em fase inicial de formação, de um Curso de Medicina de uma Universidade Pública no Estado de São Paulo (MAGALHÃES, 2020).

Destacamos que a SEI aplicada foi previamente publicada na Revista Brasileira de Educação Médica, onde todos os momentos e aulas aplicadas estão minunciosamente detalhados, no trabalho intitulado Bioquímica e Função Renal: Utilizações de Sequências Didáticas com Enfoque Investigativo para Reaproximação de Conceitos Específicos (MAGALHÃES et al., 2019).

Desta maneira, este trabalho apresenta resultados, obtidos a posteriori, sobre a percepção dos professores e alunos ao vivenciarem uma SEI, aplicada em um curso cujo currículo é fundamentado na PBL. A sequência de aulas foi realizada durante o módulo quatro, dentro do conteúdo de Homeostase, pertencente ao segundo semestre do primeiro ano, realizada pelos professores de Bioquímica e Nefrologia da referida Instituição, onde a pesquisadora propôs a sequência, acompanhou a aplicação pelos docentes responsáveis e coletou os dados de pesquisa.

\section{As Sequências de Ensino Investigativas - SEl}

O ensino por investigação é uma abordagem didática, podendo estar vinculado a qualquer outro recurso de ensino (SASSERON, 2015). Nesta proposta, o professor deve utilizar suas habilidades, ajudando os alunos na resolução de problemas, estimulando a discussão entre os pares, e os diferentes recursos e aparatos que devem estar à disposição, considerando sempre os conhecimentos pré-existentes.

Esta metodologia pode ser caracterizada por possibilitar aprender sobre o que é ciência e como esta se desenvolve. Pode ou não conter práticas experimentais, ou ser também utilizada nas ciências humanas. Tem o aluno como protagonista, com a finalidade de desenvolver o pensamento científico por meio de levantamento e testes de hipóteses, elaboração de variáveis, bem como suas relações e generalizações.

Assim, mediante seus registros, controle e observações, o aprendiz poderá elaborar explicações e defender suas ideias. É consenso que a educação científica e o pensamento/cultura científica corroboram para o desenvolvimento cognitivo e raciocínio lógico dos estudantes (SUART; MARCONDES, 2009; CARVALHO, 2013; SASSERON, 2015). 
Dentro dessa proposta, o professor deve valorizar os erros do aluno, mostrando a importância de se construir novas hipóteses explicativas. Para produzir uma aprendizagem significativa individual e coletiva apropriada (AUSUBEL, 1968), deve-se almejar a aguçar motivações intrínsecas dos alunos e regular o fluxo de informações no sistema, por meio dos recursos disponíveis, preparando-os para a realidade de sua profissão.

As Sequências de Ensino Investigativas objetivam sistematizar o ensino por investigação, contextualizando e preocupando-se em alcançar um planejamento mais global (CAÑAL E PORLÁN, 1988). Assim, o modelo didático deve permitir uma articulação coerente entre as várias contribuições parciais feitas, preexistentes em um corpo teórico, para fazer uma releitura específica, a partir da didática das Ciências, das várias bases científicas que sustentam a ideia de ensino por investigação. Corroborando com esses autores, Carvalho $(2013$, p. 9) propõe que as SEl podem ser definidas como:

[...] sequência de atividades (aulas) abrangendo um tópico do programa escolar em que cada atividade é planejada, do ponto de vista do material e das interações didáticas, visando proporcionar aos alunos: condições de trazer seus conhecimentos prévios para iniciar os novos, terem ideias próprias e poder discuti-las com seus colegas e com o professor passando do conhecimento espontâneo ao científico e adquirindo condições de entenderem conhecimentos já estruturados por gerações anteriores (CARVALHO, 2013, p. 09).

Carvalho (2013) defende que, no ensino de ciências, a experimentação passa a ser uma estratégia metodológica de ensino, pois durante sua execução o professor deve levantar questões que levem o aluno a tomar consciência por meio do raciocínio lógico e uso de inferências, propondo estratégias para resolver o problema. Neste processo, a importância do erro na construção de novos conhecimentos deve ficar clara para o professor.

Processos de frustração, reflexão, repetição, entre outros, também são, segundo a autora, essenciais para que o aluno vivencie seu próprio raciocínio e não o do professor (SUART; MARCONDES, 2009; CARVALHO, 2013). Dentro das SEl, as discussões devem ocorrer em todas as fases, uma vez que a comunicação e colaboração entre professores e estudantes são muito importantes. Assim, o aprendizado ocorre de maneira não linear, podendo surgir novos questionamentos, os quais devem ser explorados por novos ciclos investigativos (SASSERON, 2015). Entretanto, as SEl vêm sendo exploradas mais rotineiramente na Educação Básica.

No ensino superior, de maneira geral, tanto os professores quanto os alunos tiveram apenas a oportunidade de vivenciar atividades experimentais por meio de roteiros, ou protocolos fechados, ou seja, sem abertura. Nesse tipo de atividade, deve-se seguir à risca os passos, que automaticamente levam à solução esperada, em que o aluno passivo não tem espaço para argumentação e exercício do pensamento crítico. Muitas vezes, o resultado esperado já está descrito nos roteiros.

Ao aumentar o nível de abertura nas atividades experimentais, dentro de uma SEl, aumentamos a exigência cognitiva e promovemos autonomia (CARVALHO et al., 1999). Nesta perspectiva é que buscamos identificar como as SEl são percebidas pelos estudantes na área de ciências da saúde, cujo currículo é constituído com base na PBL. 


\section{A Aprendizagem Baseada em Problemas - PBL}

O programa de aprendizagem denominado Problem Based Learning - PBL surgiu no Canadá, na Mc-Master University, em 1966. Porém, apenas nos primeiros anos do século $X X I$, verificou-se o crescimento da adoção da PBL nas diversas áreas do conhecimento, como contabilidade, engenharia, áreas da saúde, entre outras (CONCEIÇÃO; MORAES, 2018; MARTINS; ESPEJO, 2015). De acordo com os autores, a PBL, atualmente, é a proposta metodológica mais utilizada em cursos médicos brasileiros, pois pode promover a aprendizagem cooperativa com foco na construção do conhecimento de forma ativa, propiciando maior entrosamento entre os discentes e maximizando a interação entre ensino, assistência e pesquisa.

É consenso, no ensino atual, a necessidade de contextualizar e problematizar as atividades de ensino e aprendizagem em uma proposta integrada. Assim, surgiu a necessidade de repensar os currículos de modo que estes viessem a integrar o saber científico como um todo, e não como partes isoladas deste todo (ABREU NETO et al., 2006). Dentre as propostas pedagógicas utilizadas para as reformulações curriculares, podemos destacar a flexibilização da estrutura curricular, que criou possibilidades (tempo) para outras atividades que favoreçam a formação humanística do estudante (HMELO-SILVER, 2004).

Em qualquer fase da educação, precisamos de estratégias metodológicas que desenvolvam e priorizem habilidades individuais, inerentes à realidade vivenciada (MALHEIRO; DINIZ,2008). Estas estratégias de ensino devem utilizar analogias, modelos, experimentação e representações em que o aluno motivado seja o protagonista (BARROWS, 1986; CARVALHO, 2013; CAÑAL; PORLÁN, 1987). A estrutura da PBL foi concebida justamente para que o aluno desenvolva habilidades e capacidades para proceder à investigação de forma planejada e sistemática; para aprender a trabalhar em grupo cooperativo e alcançar os resultados da pesquisa, de forma satisfatória, favorecendo também sua aprendizagem individual.

Para o desenvolvimento desta pesquisa, levamos em consideração que é na fase inicial de qualquer formação que ocorre o processo de transição e adaptação. No ensino superior, essa fase é muito importante para a integração e aquisição de competências ao longo do curso (TEIXEIRA et al., 2018). Há uma necessidade premente de se repensar o processo de ensino e aprendizagem e as práticas em saúde até então vivenciadas pelos profissionais, familiarizados com práticas pedagógicas tradicionais.

Como descrito acima, para todo início de curso, independente do nível escolar, podem ocorrer problemas e adaptações, principalmente durante mudanças bruscas de metodologia de ensino. Moraes (2019) aponta discordâncias sobre a condução do processo de implantação nos primeiros anos da graduação de um curso, neste caso de Medicina. Ressalta a falta de capacitação dos docentes frente às novas propostas pedagógicas, relatando que:

[...] a grade curricular nova, que traz uma proposta mais interativa, não foi facilmente assimilada pelos docentes, que precisam passar por capacitação [...] os professores precisam ser capacitados e esta exigência os tira da zona de conforto, cria um novo desafio que demanda estrutura emocional para que reconheçam as próprias limitações (MORAES, 2019, p. 01). 
Apesar de os cursos de graduação estarem optando por instituir sua proposta pedagógica na PBL (BARROWS, 1986; GOMES et al., 2009), as pesquisas apontam a necessidade de cursos de atualização e de formação continuada para os docentes. Uma importante característica da PBL é a formação de uma equipe de trabalho interdisciplinar. Os problemas devem ser elaborados em colaboração pelos professores das diferentes áreas visando à integração conceitual, além de se sugerir abordagens biológicas, psicológicas e socioculturais (GOMES et al., 2009).

Tal reestruturação se faz necessária, uma vez que os processos de ensino e aprendizagem tradicionais não apresentam mais sentido ao educando, o que promove o desinteresse. A proposta metodológica da PBL ajuda a atender às necessidades dessa nova geração de alunos, tendo em vista que o desejo de participação e comunicação num ambiente interativo e colaborativo com utilização de ferramentas tecnológicas é a grande marca dessa geração. Porém, é necessário:

Trabalhar o professor que está chegando e não tem a formação para trabalhar com o PBL, não tem nem ideia do que é o $\mathrm{PBL}$, e estão tão acostumados a lecionar que não aceitam o desafio da mudança. Por ser a primeira experiência dos alunos com o PBL, eles não têm ideia do que é o PBL. Pois, é muito usual o aluno ir para a sala de aula se sentar e não ter lido o material antes da aula. A visão deles do professor é: "Você fala comigo, você me ensina". Agora, com o PBL é diferente, eles têm como desafio realizar o trabalho, eles buscam a informação, porém eles não estão acostumados a isso. Eles não sabem como fazer isso. Então, eles ficam muito frustrados e avaliam negativamente o PBL (MARTINS; ESPEJO, 2015, p. 104).

Nesta perspectiva e diante do exposto, defendemos que as SEl, fundamentadas para a educação básica, podem auxiliar professores e alunos para trabalhar nos preceitos da proposta PBL, pois, operacionalizando as aulas e favorecendo a integração de conteúdos específicos, contextualizados, podem suprir os anseios dos alunos contemporâneos e auxiliar os docentes na adaptação dos novos currículos.

\section{Metodologia}

Caracterizamos esta pesquisa como uma pesquisa de cunho qualitativo. O curso de graduação em Medicina, no qual foi realizada esta pesquisa, foi iniciado em 2018 e optou por utilizar a PBL em seu projeto político pedagógico (PPP), em sintonia com as Diretrizes Curriculares Nacionais (BRASIL, 2014) para os cursos de Medicina (Conselho Nacional de Educação - Resolução N. ${ }^{\circ}$ 3, de 20 de junho de 2014). A pesquisa foi desenvolvida com 24 alunos e dois docentes do $1^{\circ}$ ano do Curso de Medicina de uma Universidade Pública do interior de São Paulo. Todos compreenderam o objetivo da pesquisa, concordaram e assinaram o Termo de Consentimento Livre e Esclarecido (TCLE).

Para constituir os dados desta pesquisa, foi aplicada aos alunos uma SEl, fundamentada em Carvalho (2013) e Cañal et al. (1997), validada e previamente publicada (MAGALHÃES, et al., 2019). Na realização da SEl, os alunos utilizaram seus conhecimentos de fisiologia renal e bioquímica para planejar e executar experimentos, totalizando sete aulas de 50 minutos cada. Os alunos foram divididos em grupos de cinco integrantes e participaram, voluntariamente, tanto das aulas quanto da coleta de dados. 
Os instrumentos de coleta foram utilizados em dois momentos. O primeiro foi uma entrevista gravada com docentes (2 docentes do módulo onde foi aplicada a SEI), identificados como P1 e P2 e o segundo, um questionário preenchido por 24 discentes, identificados como A1 a A24. Ressaltamos que as questões propostas, tanto na entrevista docente quanto no questionário discente, visaram responder aos objetivos da pesquisa, sob olhar dos referenciais teóricos (BARROWS, 1986; CARVALHO, 2013; CAÑAL; PORLÁN, 1987). Ambos foram integralmente transcritos e analisados. No decorrer dos resultados, serão apresentados de um a dois exemplos de menções transcritas, de forma total ou parcial.

Assim, os trechos obtidos pela entrevista e pelo questionário foram identificados como X.Y.Z/ (A ou P) N, onde X é a categoria, Y é a subcategoria e $Z$ é a unidade de sentido. A letra A significa aluno, enquanto a letra $\mathrm{P}$, professor e o $\mathrm{N}$ é a identificação. Por exemplo: 2.3.2/A10 se refere à categoria 2, subcategoria 3, unidade de sentido 2, mencionada pelo Aluno de número 10; 1.2.1/P1 se refere à categoria 1, subcategoria 2, unidade de sentido 1, mencionada pelo Professor de número um.

A metodologia de análise utilizada foi a de Análise de Conteúdo (BARDIN, 2011). Neste tipo de análise, tratamos informações adquiridas a partir de mensagens, realizando uma análise dos "significados" (classificada como temática) ou dos significantes (análise dos procedimentos). Nesta pesquisa foi utilizada a análise temática, sendo realizada a préanálise, a exploração do material, o tratamento dos resultados e a interpretação. Na última etapa, ocorreu a análise reflexiva e crítica, culminando nas interpretações inferenciais, mais uma vez sob as lentes dos referenciais teóricos. Desta forma, analisamos as entrevistas e questionários que resultaram em três categorias estabelecidas a posteriori, em que se obteve os resultados de pesquisa e suas reflexões. A questão de pesquisa proposta foi: Dadas as aproximações metodológicas entre a SEI e PBL, quais os impactos da SEI durante o processo adaptativo à PBL?

\section{Resultados e discussão}

Tanto as SEl quanto a PBL visam formar alunos independentes que podem continuar aprendendo por conta própria na vida e nas carreiras escolhidas. Assim, é responsabilidade do professor nortear o estudo e fornecer orientações e recursos educacionais que facilitem seu aprendizado. Como fundamentado, para instigar os alunos na busca do conhecimento, é importante que as problematizações e contextualizações sejam baseadas em questões do mundo real dos estudantes e das respectivas necessidades profissionais (CAÑAL; PORLÁN, 1987; CAÑAL; PORLÁN, 1988; BARROWS, 1986; CARVALHO, 2013; TEIXEIRA et al., 2018).

De maneira geral, a partir da observação durante a realização da SEI e dos resultados das transcrições dos objetos de pesquisa, pudemos observar a aprovação da SEl pelos alunos que a vivenciaram. A aprovação foi corroborada pelos docentes que participaram das atividades, sendo um Professor Doutor da Clínica Médica (P1) e um Professor Doutor da disciplina de Bioquímica Básica (P2).

Observamos que, apesar das questões propostas no questionário dos alunos e na entrevista docente serem diferentes, as análises resultaram nas mesmas unidades de sentido, subcategorias e consequentemente categorias (Figuras de 1 a 3). Foram obtidas as categorias de 1 a 3: "O Papel do Professor na SEl", "Recursos Didáticos Presentes na SEl" e "A SEl como proposta metodológica nos currículos PBL". A Figura 1 esquematiza a síntese da análise de conteúdo referente à categoria 1: "O Papel do Professor na SEI". 


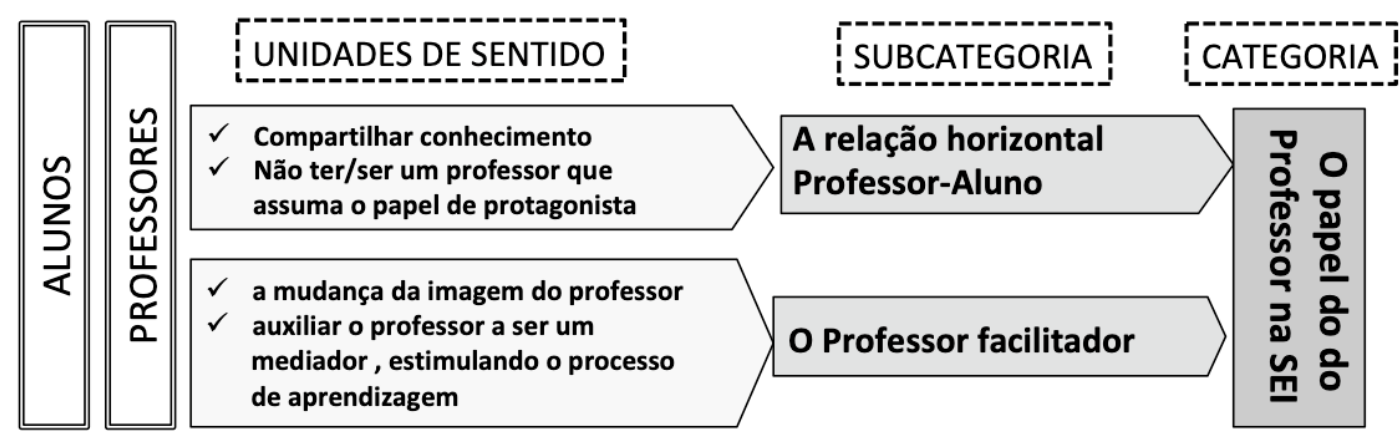

Figura 1: Unidades de sentido obtidas da Análise de Conteúdo dos questionários dos alunos e da entrevista docente e suas respectivas subcategorias, referente a categoria 1: O Papel do Professor

Assim como relatado pelos estudantes e pelos professores P1 e P2, ambos apontam a intenção de compartilhar o conhecimento. É consenso que a relação professor-aluno deve ser horizontal (subcategoria 1.1).

1.1.1/P1: "Então tem que sair daquele padrão né, daquele patamar que o professor é o foco e ele sabe tudo".

Assim, na PBL, o professor norteia os alunos na construção do novo conhecimento que será adquirido a partir do conhecimento prévio (TIBÉRIO et al., 2003). Nessa relação, tanto professores quanto alunos concordam que o professor não deve assumir o protagonismo. Isso resultou na subcategoria que propõe que a relação entre professor e aluno deva ser horizontal.

Recomenda-se que o professor deve evitar fornecer informações prontas, sendo facilitador, promovendo autonomia crescente na aquisição de conhecimentos (MARTINS; ESPEJO, 2015). No levantamento dos dados, observamos essas premissas, partindo de alunos e professores:

1.1.2/A13: "[...] cada um à sua maneira e no seu tempo e, quando necessário ou solicitado, o professor ajudava, respeitando o próprio processo de aprendizagem individual do aluno".

Almeida e Batista (2013) relatam em seu estudo que praticamente todos os professores $(94,74 \%)$ concordam que o significado do processo de aprendizagem em currículos com as chamadas metodologias ativas ${ }^{1}$ tem mudado o papel do professor. Neste sentido, a visão do professor como detentor do saber vem perdendo espaço, ou seja, o professor não deve ser o único a ter a verdade absoluta.

Devemos levar em consideração que, durante o processo de estudo para o vestibular, muitos jovens se isolam e aprendem a estudar sozinhos, com repetição e memorização de exercícios e teorias, muitas vezes com sistema apostilado. Segundo Barrows (1986), a base da PBL deve ser a aprendizagem que desenvolve as funções intelectuais, descaracterizando o processo de educação de cunho memorístico, modelo que geralmente prevalece no período anterior ao ingresso no Ensino Superior. A subcategoria 1.2 "O professor facilitador

\footnotetext{
${ }^{1}$ Nesta pesquisa, partimos do pressuposto que a citação metodologia ativa ou metodologias ativas citadas por muitos autores, englobam um conjunto de metodologias de aprendizagem ativa, ou seja, propostas de ensino centradas no aluno. Neste estudo, enfatizamos metodologias já consolidadas na literatura, a SEl e a PBL, as quais consideramos que são metodologias de aprendizagem ativa.
} 
do processo de aprendizagem" foi obtida por meio de unidades de sentido onde a imagem e o papel do professor mudaram.

Como vimos, tanto na PBL como na SEl, o professor assume um papel educacional bastante diferente daquele do ensino tradicional. Ele deve estimular os alunos a trabalharem juntos, resolvendo problemas no grupo. Na PBL o professor é chamado de tutor (GOMES et al, 2009), e essa mudança de nominação surgiu para deixar claro a ambos (professores e alunos) o seu papel de mediador do processo. Referindo-se às atividades propostas na SEI, destacamos as menções destacadas abaixo.

1.2.1/A2: "[...] o professor deve guiar e corrigir se necessário, não expor como um livro, isso já temos".

1.2.2/A5: "Vejo as atribuições do professor relacionadas a auxiliar o aluno a buscar conhecimento e orientá-lo nesse processo, não apenas como um transmissor de informações".

Assim, pela nossa análise, as unidades de sentido nos mostram que os alunos anseiam ter um professor facilitador, que os estimule no processo de aprendizagem. Ficou explícito que, além da mediação em busca do aprendizado, o desafio maior dos professores contemporâneos é de estimular os alunos na busca pelo conhecimento, transferindo responsabilidades, como pudemos perceber pela fala:

1.2.2/P1: "[...] baseada numa situação ou problema, ela se torna muito mais interessante. Eles ficaram muito excitados durante a execução e depois, o posterior, de estarem até surpresos do quanto eles entenderam o que eles fizeram e porque eles fizeram".

É indiscutível a importância em despertar o interesse do aluno, para que assim ele adquira novos conhecimentos (CARVALHO, 2013). O Professor P2 deixa claro a empolgação vivenciada pelos alunos durante as atividades "Você vê que os alunos estão realmente ali mais ansiosos, e mais empolgados para fazerem esse tipo de, de proposta (3.2.2/P2)".

Vimos nesta categoria, que o papel do professor contemporâneo vai além de mediar a aprendizagem. A mudança deve ser realizada de forma gradual para não ocorrerem prejuízos no processo de ensino. Professores e alunos vislumbram a necessidade das mudanças, devido ao acesso fácil a informações no mundo globalizado. Muitos autores descrevem a eficácia da PBL (ALBANESE; MITCHELL, 1993; BARROWS, 1986; HMELO-SILVER, 2004). Porém existe uma necessidade de pesquisas na área, principalmente no que diz respeito às estratégias metodológicas adaptativas fundamentadas para inserção das chamadas "metodologias ativas" (TEIXEIRA et al., 2018).

A categoria 2 "Percursos didáticos presentes na SEl" (Figura 2) é constituída de três subcategorias. A primeira subcategoria é a utilização do problema de partida como instrumento para a motivação (2.1). Essa subcategoria envolve questões de problematização e contextualização (RICARDO, 2010; CARVALHO, 2013).

O problema de partida da SEI envolvia atividades experimentais investigativas, com alto grau de abertura (MUNFORD; CASTRO LIMA; 2007). Os alunos A15 e A19 mencionaram encontrar dificuldades nesta etapa. "Houve uma dificuldade inicial para entender o problema proposto (2.1.1/A15)" e "[...] as instruções dadas estavam um pouco confusas, de início, foi difícil entender o objetivo para o qual nos planejarmos" (2.1.1/A19). 


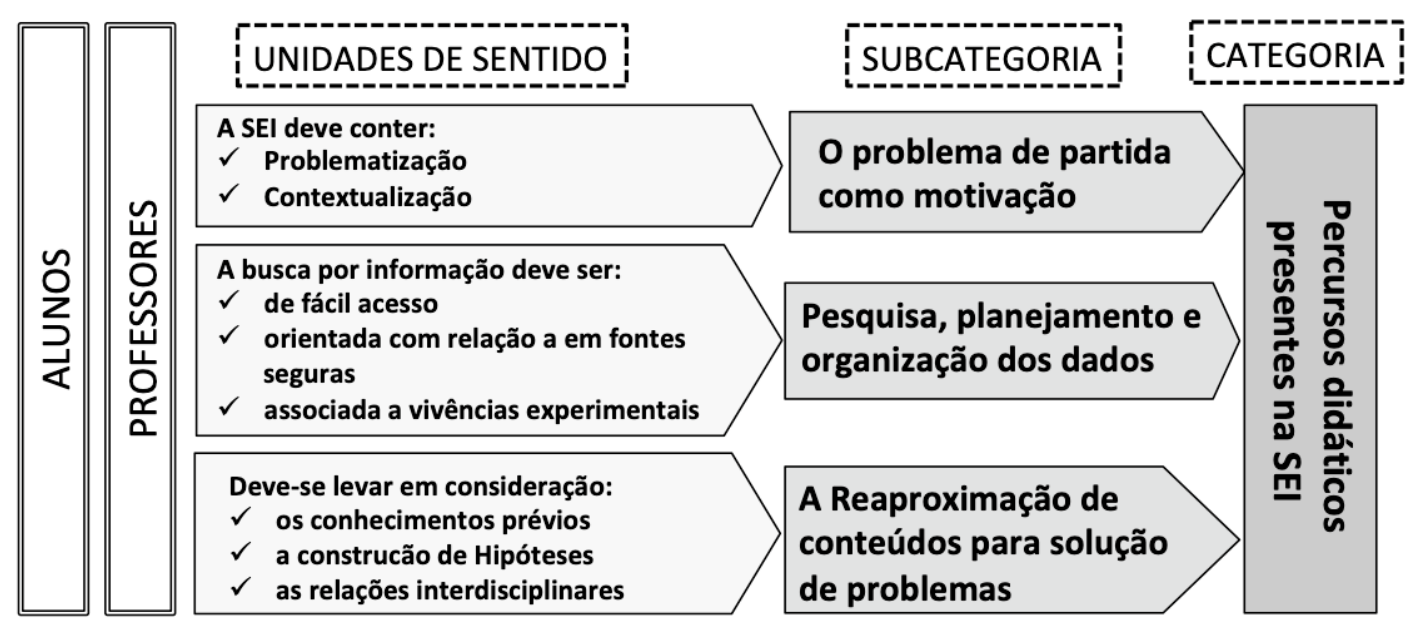

Figura 2: Unidades de sentido obtidas da Análise de Conteúdo do questionário dos alunos e entrevista docente, com suas respectivas subcategorias, referentes à categoria 2: Percursos didáticos presentes na SEl

Provavelmente, os alunos relataram essa dificuldade por vivenciarem uma SEI com alto grau de abertura. De fato, muitos alunos mencionaram oralmente nunca terem tido aulas práticas de laboratório, e os que as vivenciaram relataram aulas demonstrativas ou tradicionais, tendo as etapas descritas em um roteiro pré-estabelecido.

A SEI foi contextualizada com um caso clínico envolvendo conceitos de Proteinúria (MAGALHÃES, et al. 2019). Com relação às contextualizações propostas, o Professor P2 menciona:

2.1.1/P2: "Então foi feita integração com a professora específica de renal. [...] o que leva o aluno a fazer essa contextualização, essa integração, em termos de conteúdo, em termos de conceitos; [...] fazendo com que o professor tenha uma atividade mais pró-ativa nesse sentido, também saia da sua zona de conforto, mas acaba tentando contextualizar melhor alguns conceitos, principalmente na área básica que é o meu caso, bioquímica. Então a integração era muito difícil, o professor lá no primeiro ano tentava contextualizar alguma coisa que, talvez ele veria só no terceiro, quarto ano, mesmo fora de uma aproximação com outras disciplinas básicas. Era uma coisa muito, muito engessada. E à medida que a estrutura curricular foi modificada, modelada e que os corpos docentes e as comissões de graduação começaram a pensar nesse sentido, hoje existe uma proposta melhor pra essa contextualização e essa aproximação de conteúdo teórico, conteúdo básico com a vivência clínica".

A segunda subcategoria 2.2 refere-se à pesquisa, planejamento e organização dos dados. Uma vez que as propostas metodológicas deste trabalho colocam o aluno como protagonista na busca de seu conhecimento, no caso da SEI em atividades abertas. Munford e Castro Lima (2007) descrevem que quanto mais aberta for a atividade experimental investigativa, maior o protagonismo do aluno e consequentemente melhor a aprendizagem. Dada esta autonomia, na qual o aluno será responsável pela busca de informações, os professores devem se preocupar com relação à organização e orientação da busca pelo conhecimento (CARVALHO, 2013; CAÑAL; PORLÁN, 1988) a partir de fontes confiáveis.

Essa subcategoria nos mostrou que os alunos têm fácil acesso à pesquisa, conforme mencionou o Aluno A11 "As facilidades foram possuir meios de pesquisa de forma rápida, para estabelecer uma direção de quais caminhos seguir" (2.2.1/A11). Porém alguns alunos 
relataram dificuldades "em fontes confiáveis para servirem de base para começar a traçar um plano" (2.2.2/A2). O professor P1 deixa claro na sua fala a preocupação com as fontes "se ele for pensar só lá, embora que a gente saiba que ele possa jogar na internet, no Google, eu acho que mesmo que o planejamento inclua isso sabe, eu vou precisar jogar na internet pra conseguir ai determinadas informações" (2.2.2/P1).

Como última unidade de sentido nesta subcategoria (2.2), temos a unidade de sentido relacionada à falta de vivências experimentais. Foram muitas menções com relação a esse tópico, pois muitos nunca haviam adentrado a um laboratório, como no relato do aluno que indica ter "Dificuldade em planejar uma atividade em laboratório por nunca ter utilizado um (2.2.3/A8)". Isso nos leva à seguinte reflexão: se graduandos em medicina não tiveram vivências laboratoriais na educação básica, quais alunos tiveram?

Como esperado, este problema resultou em dificuldades para a realização de um planejamento experimental. Segundo eles:

2.2.3/A3: "Apresentei muita dificuldade em como fazer o planejamento, pois achei um pouco confuso, tendo em vista que nunca tinha feito isso antes".

Considerando inovadora, os professores que participaram da SEI, aprovaram a proposta, principalmente com relação à atividade experimental investigativa. Podemos observar pela fala do professor $\mathrm{P} 2$ :

2.2.3/P2: "Não sei se será uma questão posterior, mas eu achei que a parte no laboratório foi muito, muito, muito, muito boa, por conta de os alunos vivenciarem, descobrirem, interagirem bastante entre eles e com o que tinha disponível e na bancada para eles".

Finalmente, nesta categoria, temos a última subcategoria "Reaproximação de conteúdos para solução de problemas" (2.3). Essa subcategoria mostra a importância dos conhecimentos prévios para a resolução de problemas (SASSERON, 2015; CARVALHO, 2013) e discute a importância da interdisciplinaridade para iniciar um bom planejamento e propor hipóteses (BARROWS, 1986; CARVALHO, 2013; HMELO-SILVER, 2004; MAGALHÃES, et al. 2019). O aluno A7 relatou que sua "maior dificuldade consistiu no fato de ter que relembrar e pesquisar assuntos já esquecidos" (2.3.1/A7) e por outro lado, o aluno A22 descreve ter facilidade "devido a conhecimentos prévios capazes de prever a substância prevalente na urina" (2.3.1/A22). Assim, segundo o aluno A7, a dificuldade está em retomar os conteúdos esquecidos, e ambos concordam com a necessidade do saber prévio para iniciar o planejamento e conseguinte levantamento de hipóteses. Do mesmo modo, o professor P1 reitera tal importância pela fala:

2.3.1/P1: "Ele lança a situação, a situação ou o problema né, e dá ferramentas para que o aluno vá atrás das próprias perguntas, baseados no conhecimento prévio que ele tem, ou seja, do ensino fundamental, ou seja do cursinho, e em cima disso ele construa o seu próprio conhecimento".

Nesse sentido, Barrows e Tamblyn (1980) apontam que na PBL o estudante é estimulado a construir ativamente sua aprendizagem, articulando seus conhecimentos prévios, compartilhando conhecimentos por meio das discussões com seu grupo. Sasseron (2015) e Carvalho (2013) relatam que essas discussões, muito comuns na SEl, promovem argumentação científica entre os alunos e professor e, consequentemente, resultam em alfabetização científica. 
Devemos desenvolver atitudes e habilidades de todos os tipos, características da ciência e do trabalho científico (CAÑAL; PORLÁN, 1988). Observamos, assim, a menção do aluno A11, que se refere à importância do "fazer ciência":

2.3.2/A11: "Isso foi notado pelo fato de ficarmos livres para propor um método de comparação que se tornou eficaz diante dos resultados alcançados".

Tanto a PBL quanto a SEI se fundamentam em propostas interdisciplinares (BARROWS, 1986; CANAL et al., 1997; CARVALHO, 2013, HMELO-SILVER, 2004). Isso provoca os especialistas da área de ensino em ciências para repensarem os currículos (GOMES et al., 2009). É preciso pesquisar sobre essas mudanças e construir gradualmente propostas mais ativas, uma vez que o perfil do aluno mudou e não podemos correr contra o tempo. Devese determinar os conteúdos das disciplinas e sua integração, ligando-as a outras disciplinas dos anos subsequentes, com complexidade crescente e tomando o cuidado para evitar repetições (TIBÉRIO et al., 2003). Nesse sentido, alunos apontam que:

2.3.3/A13: "Foi no sentido de poder ver na prática como o conhecimento das ciências básicas é essencial para a prática médica no futuro".

A fala do professor P1, referente à interdisciplinaridade nos chamou a atenção "Isso sempre foi um grande problema. Uma grande celeuma mesmo. Eu vou falar de novo, especificamente, do curso médico. A gente até brincava que os primeiros dois anos do curso não era medicina" (2.3.3/P1). Ele acredita que "o conceito de metodologia ativa que engloba integração entre o básico e a clínica, fica uma terra muito mais fértil" (2.3.3/P1). E relata:

2.3.3/P1: "Quando o P2 e você me procuraram eu falei nossa, que coisa interessante né. Porque que eu achei superinteressante, porque primeiro assim: porque eles viram o porquê a bioquímica é importante né. Como a gente transpõe esse conhecimento básico para aplicação clínica. Só que aqui não usa 5\% do raciocínio que vocês utilizaram lá. Então eu acho que conseguiu integrar de uma maneira assim, muito é ... adequada. Olha como entender uma reação química pode me auxiliar a interpretar um exame de urina 1. Que aquela fitinha nada mais é do que um monte de reação química. Se eu quiser identificar glicose, se eu quiser identificar albumina, é a mesma coisa".

Segundo Teófilo et al. (2017), a perspectiva de integração curricular, substituindo as disciplinas tradicionais pelos módulos integrados, é promissora. Os autores discutem de que maneira as complexas questões metodológicas envolvidas na mudança das escolas são tratadas e reiteram que a mudança nos currículos é necessária para contemplar o perfil do egresso contemporâneo. Apesar disso, ainda há muita resistência dos docentes e dirigentes das instituições (CONCEIÇÃO; MORAES, 2018; MARTINS; ESPEJO, 2015; MORAES, 2019).

A última categoria encontrada nesta pesquisa foi intitulada "A SEl como proposta metodológica nos currículos PBL". Assim, como as outras categorias anteriores, as menções dos professores e alunos originaram as unidades de sentido e as suas respectivas subcategorias. A Figura 3 esquematiza a síntese dessa análise.

Esta categoria foi o resultado de duas subcategorias: $O$ aluno Protagonista e Percepções dos alunos sobre a atividade experimental investigativa desenvolvida na SEI. A subcategoria "O aluno protagonista" nos mostrou que os alunos consideraram a atividade (SEI) como uma proposta ativa de aprendizagem, como podemos observar:

3.1.1/A19: "[...] pois fogem do ambiente de aprendizado tradicional de sala de aula e/ou prática laboratorial com roteiro fixo, enrijecido". 


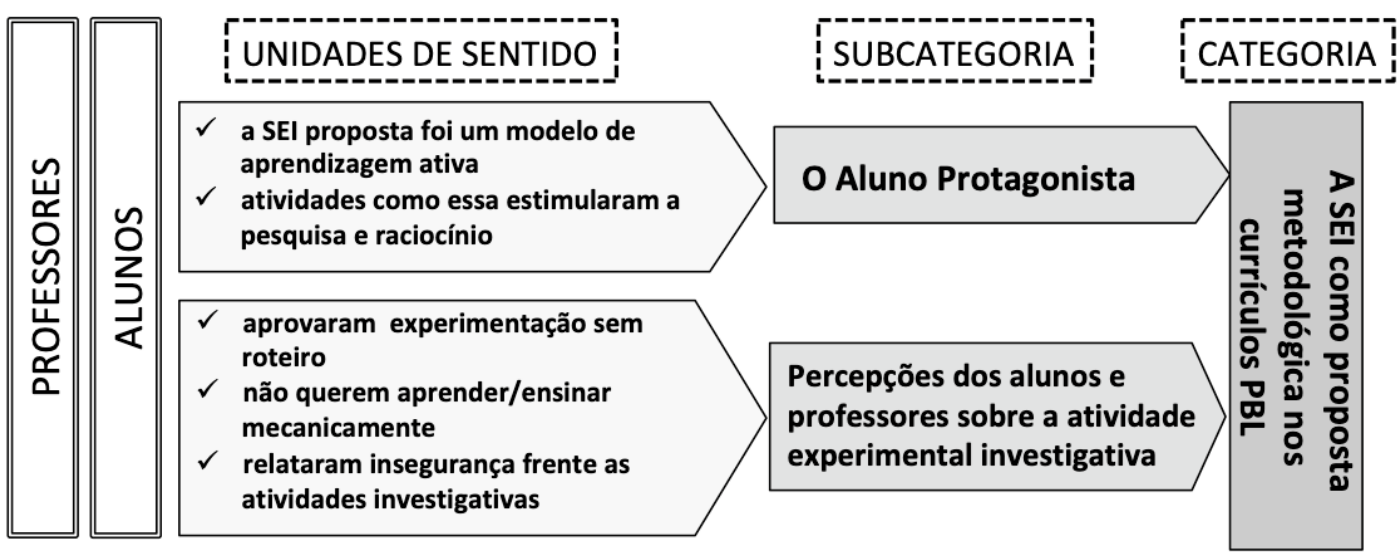

Figura 3: Unidades de sentido obtidas da Análise de Conteúdo do questionário dos alunos e entrevista docente e suas respectivas subcategorias, referente a categoria 3: A SEI como proposta metodológica nos currículos PBL

Vale a pena mencionar que esta unidade de sentido foi encontrada em todos os questionários, ou seja, a totalidade dos alunos concordaram que esta atividade os mantinha no protagonismo do processo de aprendizagem. Agora cabe questionar se eles sabem, de fato, o que são metodologias de ensino com propostas ativas ou não, principalmente no que diz respeito a atividades experimentais, dentro da proposta da SEI realizada, que foi além dos conteúdos conceituais, englobando os conteúdos procedimentais e atitudinais (MAGALHÃES, et al. 2019).

Nesse sentido, podemos refletir que os estudantes, ao aprovarem a ideia "do novo", estão de acordo com os objetivos propostos pela PBL (BARROWS, 1986; TEIXEIRA et al., 2018), pois intrinsecamente sabem que se depararão com problemas para os quais não terão um "roteiro preestabelecido". Afirmações como do aluno A2 "Não recebemos a matéria pronta, a busca por uma solução foi ótima para aprendizado" (3.1.1/A2) corrobora essa premissa.

Foram encontradas unidades de sentido que indicam que A SEl estimulou a pesquisa e o desenvolvimento do raciocínio. Em especial, a fala do aluno 18 (3.1.2/A18) chamou a atenção "[...] buscar as informações específicas e necessárias para a realização da atividade, com pouco conhecimento anterior a ela, sendo mais difícil, estressante e cansativa, porém com melhores resultados, mais absortivos", mostram que atividades que fazem pensar e tiram o aluno da "zona de conforto" podem produzir aprendizagens mais eficientes (AUSUBEL, 1968).

A subcategoria 3.2 está relacionada às Percepções dos alunos sobre a atividade experimental investigativa, que foi desenvolvida na SEI. Inicialmente, os alunos encontraram dificuldades para compreender a proposta. Durante a pesquisa, percebi também a expressão facial de susto e, apesar de serem alunos dedicados, relataram oralmente surpresa ao receberem a proposta. O professor P1 (3.2.3/P1) usa os seguintes dizeres: "[...] desde a fase da ansiedade, da insegurança do início". Carvalho (2013) aponta a importância de se deixar claro para o aluno o problema, os recursos e os objetivos do experimento investigativo, porém como foi a primeira experiência nessa proposta, eles apresentaram receio, que foi se ajustando com o decorrer da SEI. 
Deste modo, a princípio, acreditavam que não seriam capazes e estavam muito inseguros. Apesar disso, após a realização da SEI, nove dos 24 alunos mencionaram explicitamente nos questionários preferirem atividades sem roteiro.

3.2.1/A2: "[...] estaria só executando, sem estudo, pesquisa, pró-atividade".

O que nos chamou atenção foi a fala do professor P2 (3.2.2/P2) "Como eles trazem uma proposta, eles estão num nível de atenção, empolgação maior do que em uma aula prática tradicional com roteiro já pré-estabelecido".

Segundo os pressupostos do Ensino por Investigação (CAÑAL; PORLÁN, 1988; CARVALHO, 2013), o levantamento de hipóteses e o planejamento são etapas importantes no processo de aprendizagem. Em grupo, os alunos recordam saberes e constroem novos a partir de uma proposta que os instigue a buscar soluções. De fato, ao final da aula prática, presente na SEI, o que mais chamou atenção foi o entusiasmo dos alunos ao chegarem à resolução do caso clínico a partir dos experimentos por eles planejados.

De acordo com os pressupostos da PBL, o aluno deve ter autonomia e ser responsável pelo seu aprendizado (BARROWS, 1986). Nesse sentido, a SEl aplicada corrobora na promoção da autonomia do aluno. Na unidade de sentido "A SEl estimulou a pesquisa e raciocínio", os professores relatam:

2.1.2/P1: "Vamos fazer um experimento, mas não era com essa autonomia que foi dada aos alunos. Claro que vocês estavam lá, supervisionando, mas os alunos tiveram a autonomia de ver como que eles iam fazer essa investigação".

Nesta mesma subcategoria (3.2) surgiu a unidade de sentido que mostra que os alunos não querem aprender e nem os professores ensinar mecanicamente.

3.2.2/A17: "Seria feita de forma mecânica, sem análise crítica acerca dos métodos".

Assim como os alunos, os professores que acompanharam a SEl relataram a aprovação da experimentação investigativa pelo fato de o aprendizado não ser "mecânico". Podemos observar na fala de P2 "Você o tira da zona de conforto, põe ele pra pensar. Difere um pouco da forma tradicional, quer dizer, a gente tem ainda hoje aula prática com roteiro né, definido, o aluno vai e repete tudo aquilo que a gente faz, tudo, e ai ele chega, todos vão chegar, se fizerem corretamente, na mesma conclusão" (3.2.2/P2).

Foram explicitadas pelos alunos menções sobre a SEI desenvolver o interesse. Cañal e Porlán (1988) citam a importância de desenvolver atividades no campo dos interesses dos alunos, o que eles chamam de desenvolvimento de motivação intrínseca. Na proposta aplicada, os relatos dos alunos A9 e A24 (3.2.3/A9 e 3.2.3/A24) que vivenciaram a SEl, corroboram com essa perspectiva. O aluno A9 diz que experimento com roteiro préestabelecido "[...] seria pior, pois a gente passaria a seguir passos como "máquinas" sem aplicar nosso conhecimento e instigar nossa curiosidade" e A24 diz que "[...] seria pior, pois seria bem menos interessante e eu me envolveria menos".

Por outro lado, o aluno A6 (1.2.3/A6) aprovou a atividade sem roteiro, porém relatou insegurança: "A ausência de um roteiro prévio permite maior liberdade ao aluno, mas também pode deixá-lo inseguro sobre como agir. A constituição de um roteiro experimental mais flexível e aberto a adaptações seria adequado, pois coíbe a autonomia do estudante e, ao mesmo, sugere maneiras de como iniciar e conduzir o experimento". Nesta resposta, o aluno sugere um roteiro parcialmente aberto. Nesse sentido, seria possível realizar uma investigação estruturada, com nível de abertura intermediária (MUNFORD e CASTRO LIMA, 2007), em que o objetivo é dado, o material e o método são dados em parte, deixando aberta apenas a solução. Isso nos mostra mais uma vez que precisamos investir na 
implementação da proposta PBL, que demanda processos adaptativos e acreditamos que as SEl podem ser utilizadas para este fim. Além disso, com a inserção da SEl no currículo baseado na PBL, podemos aumentar o interesse dos alunos pelas ciências básicas, como neste estudo pela bioquímica básica, mostrando a importância das conexões entre os saberes.

\section{Considerações finais}

O ensino superior, tendo mais autonomia do que a educação básica, tem aumentado exponencialmente a inserção de propostas pedagógicas ativas, devido à necessidade de mudanças nas práticas pedagógicas que, por sua vez, têm gerado mudanças curriculares. Este fato demanda um aumento da necessidade de se realizar pesquisas na área, principalmente no que diz respeito a processos adaptativos.

Tanto a PBL quanto as SEI defendem um modelo de aprendizagem centrada no aluno, e a eficácia em ambas as metodologias está bem consolidada na literatura. A análise dos dados aponta para resultados que mostraram contribuições significativas. A SEI mostrou ter contribuído para uma melhor compreensão das características fundamentais do aprender ciências, da integração de saberes e da evolução do conhecimento, valorizando o pensamento científico, dando maior ênfase aos conteúdos procedimentais, para o uso da PBL.

Apresentamos neste artigo três categorias, obtidas por meio da análise sistemática de dados de pesquisa. Nelas observamos que o aluno deseja ter um papel central no processo de aprendizagem, e o professor deve ser um facilitador cujo maior desafio é instigar os alunos na busca pelo conhecimento, apresentando problemas interessantes e reais. Ressalta-se a importância da contextualização na proposição do problema, que tem um papel central também na PBL.

Da mesma maneira que na PBL, observamos que a SEI corroborou o ensino focado no aluno e no papel do professor como mediador do processo de ensino e aprendizagem. Além disso, a partir de uma problematização contextualizada, podemos estimular os alunos na busca pelo conhecimento prático experimental de maneira interdisciplinar, prezando pela autonomia e criatividade, ligando as ciências básicas aos conhecimentos aplicados. Nossos resultados apontaram que as atividades propostas foram capazes de estimular a pesquisa e o raciocínio. Este fato ocorreu principalmente na etapa de planejamento, onde foram levantadas hipóteses, alicerçadas nos conhecimentos prévios, na pesquisa individual e em grupo. Além disso, a pesquisa demonstrou que, de maneira geral, tanto os alunos quanto os professores aprovaram a realização de práticas experimentais investigativas, com alto grau de abertura.

Observamos, no desenvolvimento da pesquisa, que as ciências básicas estão perdendo seu espaço dentro do currículo PBL, uma vez que os alunos tendem a perder o interesse. Assim sendo, a SEl pode gerar a valorização das mesmas.

Com relação à SEl e sua aplicação, acreditamos que muitos docentes não sabem como fazer, devido à falta de formação pedagógica. De fato, no PBL, as problematizações geralmente englobam ciências aplicadas, não sendo apropriadas para os alunos recém ingressados, principalmente pela falta de conhecimentos prévios.

Levamos em consideração que, de maneira geral, os professores ensinam como aprenderam, uma vez que no ensino superior, bem como nos cursos de pós-graduação, a 
pedagogia não é valorizada. Nesse sentido, esta proposta também pode favorecer a formação do professor para se integrar de maneira mais facilitada na PBL. Além da reflexão nos cursos superiores, fundamentados na PBL, neste momento, cabe-nos refletir sobre as mudanças que ocorrerão na Educação Básica, onde o currículo ainda se mantém seriado, com disciplinas estanques, que não conversam entre si.

Diante do exposto, defendemos o uso de SEl, integradas a currículos baseados na PBL, nos ciclos iniciais, a fim de contribuir para a integração de conhecimentos, além de facilitar a integração dos estudantes ingressantes, sua adaptação à nova proposta metodológica e seus desafios.

\section{Referências}

ABREU NETO, I. et al. Percepção dos professores sobre o novo currículo de graduação da Faculdade de Medicina da UFG implantado em 2003. Rev. bras. educ. med., v. 30, n. 3, p. 154-160, 2006.

ALBANESE, M. A.; MITCHELL, S. Problem-based learning: A review of the literature on its outcomes and implementation issues. Academic Medicine, v. 68, n. 1, p. 52-81, 1993.

ALMEIDA, E. G.; BATISTA, N. A. Desempenho docente no contexto PBL: essência para aprendizagem e formação médica. Rev. bras. educ. med., v. 37, n. 2, p. 192-201, 2013.

AUSUBEL, D.P. Educational psychology: a cognitive view. New York: Holt, Rinehart, and Winston. 1968.

BARDIN, L. Análise de conteúdo. São Paulo: Edições 70, 2011.

BARROWS, H. S.; TAMBLYN, R. M. Problem-based learning: An approach to medical education. New York: Springer, 1980.

BARROWS, H. S. A taxonomy of problem-based learning methods. Medical Education, v. 20, n. 6, p. 481-486, 1986.

BRASIL, 2014. Ministério da Educação. Câmara de Educação Superior. Resolução No. 3 de 20 de junho de 2014. Diário Oficial da União, Brasília, 23 jun. 2014; Seção 1, p. 8-11.

CAÑAL, P.; LLEDÓ, A. I.; POZUELOS, F. J. Investigar En La Escuela: Elementos para una Enseñanza Alternativa. Sevilla: Díada, 1997.

CAÑAL, P.; PORLÁN, R. Bases para un programa de investigación en torno a un modelo didáctico de tipo sistémico e investigativo. Enseñanza de las Ciencias, v. 6, n. 6, p. 54-60, 1988.

CAÑAL, P.; PORLÁN, R. Investigando la realidad próxima: Un modelo didáctico alternativo. Enseñanza de las Ciencias, v. 5, n. 2, p. 89-96, 1987.

CARVALHO, A. M. P. et al. Termodinâmica: Um ensino por investigação. São Paulo: USP, 1999.

CARVALHO, A. M. P. Ensino de ciências por investigação: condições para implementação em sala de aula. São Paulo: Cengage Learning, 2013. 
CONCEIÇÃO, C. V.; MORAES, M. A. A. Aprendizagem Cooperativa e a Formação do Médico Inserido em Metodologias Ativas: um Olhar de Estudantes e Docentes. Revista brasileira de educação médica, v. 42, n. 4, p. 115-122, 2018.

GOMES, R. et al. Aprendizagem Baseada em Problemas na formação médica e o currículo tradicional de Medicina: uma revisão bibliográfica. Rev. bras. educ. med., v. 33, n. 3, p. $433-$ 440, 2009.

HMELO-SILVER, C. E. Problem-based learning: what and how do students learn? Education Psychology Review, v. 16, n. 3, p. 235-266, 2004.

MAGALHÃES, P. P. et al. Bioquímica e Função Renal: Utilizações de Sequências Didáticas com Enfoque Investigativo para Reaproximação de Conceitos Específicos. Rev. bras. educ. med, v. 43, n. 1, 2019.

MALHEIRO, J. M. S.; DINIZ, C. W. P. Aprendizagem Baseada em Problemas no Ensino de Ciências: Mudando Atitudes de Alunos e Professores. Amazônia - Revista de Educação em Ciências e Matemáticas, Belém, v. 4 - n. 8 - jan 2008/jun. 2008.

MAGALHÃES, P. P. Sequências de ensino investigativas (SEI) e aprendizagem baseada em problemas (PBL): aproximações teórico metodológicas e suas contribuições aos alunos de medicina em fase inicial de formação. 2020. 189p. Dissertação (Mestrado em Ensino de Ciências) Faculdade de Ciências, Universidade Estadual Paulista, Bauru, 2020.

MARTINS, D. B.; ESPEJO, M. M. S. B. Problem based learning: PBL no ensino de contabilidade: guia orientativo para professores e estudantes da nova geração. São Paulo: Atlas, 2015.

MORAES, T. Coordenador é exonerado de curso de Medicina da USP e fala em conspiração. JCNET, Bauru, 11 jun. 2019. Disponível em:

https://www.jcnet.com.br/noticias/geral/2019/06/556194-coordenador-e-exonerado-decurso-de-medicina-da-usp-e-fala-em-conspiracao.html. Acesso em: 10 out. 2019.

MUNFORD, D. E.; CASTRO LIMA, M. E. C. Ensinar ciências por investigação: em quê estamos de acordo? Ensaio, v. 9, n. 1, p. 89-111, 2007.

RICARDO, E. C. Problematização e contextualização no ensino de física. In. CARVALHO, A. M. P. (Org.). Ensino de Física. São Paulo: Cengage Learning, 2010. p. 29- 51.

SASSERON, L. H. Alfabetização científica, Ensino por investigação e argumentação: relações entre ciências da natureza e escola. Ens. Pesqui. Educ. Ciênc. v. 17, n. especial, p. 49-67, 2015.

SUART, R. C; MARCONDES, M. E. R. A manifestação de habilidades cognitivas em atividades experimentais investigativas no ensino médio de química. Ciência \& Cognição, v. 14, n. 1, p. 50-74, 2009.

TEIXEIRA, L. S.; ALMEIDA, L. S.; SILVA, R. A. Mudança curricular e de métodos pedagógicos: impacto vivenciado por estudantes de Medicina. Revista de estudios e investigación en psicología y educación, v. 5, n.1, 19-28, 2018.

TEÓFILO, T. J. S.; SANTOS, N. L. P.; BADUY, R. S. Apostas de mudança na educação médica: trajetórias de uma escola de medicina. Interface, v. 21, n. 60, p. 177-188, 2017.

TIBÉRIO, I. F. L. C.; ATTA, J. A.; LICHTENSTEIN, A. O aprendizado baseado em problemas PBL. Rev. Med., v. 82, n. 1-4, p. 78-80, 2003. 